\title{
The Tech-Enabled Neighborhood: Findings from an experience in Tecámac, Mexico
}

\author{
Victor M. Gonzalez ${ }^{1}$, Kenneth Kraemer', Luis A. Castro' ${ }^{1}$ and Alladi \\ Venkatesh $^{2}$ \\ 1 Manchester Business School \\ University of Manchester, United Kingdom \\ 2 Paul Merage School of Business \\ University of California, Irvine, USA
}

\begin{abstract}
Following worldwide tendencies, the patterns of usage of Information and Communication Technologies (ICT) in Mexico are being influenced by increasing affordability. In this work we present the results of a study on the use and adoption of ICTs to support daily life in residential communities conducted in Tecamac, Mexico. There, neighbors were provided with computers and broadband internet access as part of the facilities. The study consists of analysis of interviews conducted in situ with members of the community. We mainly discuss incidents and situations beyond and around the use of technology such as the services neighbors need when moving in. This study provides some insights for the design and deployment of technology in real communities on a large scale.
\end{abstract}

\section{Introduction}

Following worldwide tendencies, the patterns of usage of Information and Communication Technologies (ICT) in Mexico are being influenced by increasing affordability. The usage of personal computers at home is now more common as a result of cheaper technologies and credit plans. Related to this is the increased connectivity of family homes through dial-up lines and high-speed broadband. According to the Mexican Association of Internet, in 2005 about 20 million people have internet access, from which $43 \%$ is from home [1]. In 2005 , the number of computer with Internet access at home increased about $20 \%$ with respect the previous year [2].

In parallel, in Mexico there is a huge investment to build housing infrastructure and make it affordable, especially for low and middle-income people. After years of housing scarcity, now in Mexico more and more people are able to purchase their 
own household. These two aspects do not necessarily reflect an idealistic scenario where digital and housing divides have been eliminated; Mexico is far from that. Instead, they reflect a set of conditions where technologies are likely to impact the very conceptual bases of what we understand for homes and more generally neighborhoods; a vision that we refer here as Habitat Computing.

This paper presents the results of a study conducted to understand the practicalities of implementing a feasible vision of Habitat Computing in a Mexican neighborhood. At the beginning of 2005, in the city of Tecámac, in Mexico, Real Paraiso Residencial, a housing company, in partnership with Conectha, an Internet Service Provider, had the vision to develop a residential complex (Real del Sol) consisting of about 2000 houses all equipped with a computer and broadband internet access. Neighbors were also provided with a community portal through which they access to a variety of neighborhood-oriented online services such as message board, online shopping, ordering taxis, access to educational content and access to security video cameras around the neighborhood.

Using semi-structured interviews, we explored the factors motivating the purchase of the house, the experience of moving in, the relationships with the neighbors and the community, their use of the technology to support domestic practices as well as perspectives on how to make the technology more useful.

Our analysis reveals challenges and opportunities for the deployment of current ICT to allow residents to better integrate themselves into their community and contribute to its wellbeing. Our results also indicated that the implementation of ICTs to support daily life in residential communities might not support the, to some extent, idealistic perspective explored in previous research [3]. Social problems are very likely to arise such as disagreement among neighbors on quotidian tasks or division of labor. However, in contrast, there are other challenges faced by the neighbors and they act as sources for community integration. Our results indicate that looking for solutions for these problems could make the community more cohesive and increase their likeliness of self-organization.

\section{Some Characteristics of the Mexican Housing Context}

In recent years, housing developments for low income people have been blooming in masse all over Mexico, thanks to a federal government initiative that provides grants and mortgages. These urban settlements are usually located in the outskirts of the main Mexican cities, and they all share the same characteristics: affordable mortgages (i.e., requiring a payment of around 200 dollars a month, for over 20 years), reduced in-house areas, reduced build areas per home (usually consisting in two bedrooms at most, a bathroom, living-dining room, small patio, one parking space, and a garden), architecturally similar constructions, and heavy concentrations of houses, altogether.

Whilst this initiative is helping to solve the shortage of housing for low-income Mexican citizens, it is creating a new set of problems, previously unheard of. First, the distance between the cities main working facilities and the housing developments are considerable, often involving an hour plus commute time. Since these housing 
developments are generally built on less expensive city locations, supermarkets, hospitals, universities and the like are usually far from these projects. In some cases, the availability of phone lines may even be scarce.

Security is other main concern for the inhabitants of these housing developments. Many houses remain empty during the day, because both husband and wife often work in the city, which makes the houses susceptible to burglary. Statistics from the Mexican NGOs such as "Mexico Unido Contra la Delincuencia" point out that in Mexico City twenty percent $(20 \%)$ of all burglaries are committed in households and one in eight is reported to the authorities [4]. Facing insecurity, many Mexican housing developments have opted to create some sort of isolation for the community with the external world in order to increase the safety of the properties. Similar to other parts of the world, a common solution has been to create what is called "gated communities" in which the access to the community is controlled and physical barriers are erected to avoid intrusions [5].

Beyond physical barriers that might created just a sense (but not real) security, many authors argue that the foundations for safer and better places to live lies on the community of neighbors. The perception of living in a safe and secure housing environment can increase if the residents are unfamiliar with their neighbors $[5,6]$. Consequently, people have a lot to gain from organizing with their neighbors not just to protect each other against crime but because they can act together to improve their neighborhoods and respond with more power to shared challenges. However to achieve such organization is not easy as people lack the time to meet, discuss, plan and organize with their neighbors.

Within this context, it is possible to argue that the use of information and communication technologies (ICTs) can facilitate the creation of communities and increase with this the quality of living. This follows in spirit the work of others which aim to use ICTs to create the conditions to support the local and social interaction in urban or rural neighborhoods [3, 6-8]. For instance, in Foth's approach a socially strong community will be the result of neighbors finding out about common interests and becoming involved in door-to-door interactions. In our the characteristics of Mexican urban household with long commute distances, elevated safety concerns and particular ways to approach community life bring particular characteristics to the phenomenon of technology as community communication mediator.

\section{Characteristics of the Study and Methodology}

At the end of February 2006, we conducted a set of ethnographic interviews with families living in or about to move to Real del Sol. The housing development is located in the city of Tecámac, in the State of Mexico'. Although Tecámac is not part of the metropolitan area of Mexico City, it is close enough as to allow a reasonable

I The State of Mexico is located in central Mexico, and it almost completely encapsulates Mexico City. Some of the most populated counties in Mexico are in the State of Mexico, particularly those that comprise the Metropolitan Area of Mexico City. 
commute to the city (approximately an hour long trip, with good traffic conditions). The vast majority of inhabitants in Real del Sol work in Mexico City itself.

A total of 34 individuals were interviewed covering 27 households averaging 3 members per family ( 87 individuals in total). Interviewees have a variety of occupations, from journalists to primary school teacher, from house keepers to tourist agents. The interviews were semi-structured and covered a set of topics including the factors motivating the purchase of the houses, the experience of moving in, the relationships with the neighbors and the rest of the community, their use of the technology to support domestic practices as well as perspectives on how to make the technology more useful. Each interview lasted an average of 45 minutes and was conducted at the home of the resident. Just in two cases interviews were conducted at Conectha's offices, as the informants had not yet moved to their properties by the time of the interviews.

The interviews were complemented with a number of observations of the community and informal interviews with staff from both Conectha and Real Paraiso Residencial, as well as with people from the Ojo de Agua community (not living at Real del Sol), including taxi drivers, shop owners and security staff.

Data were analyzed using a comparative approach (inspired in Grounded Theory [9]) to identify patterns among the informant's responses and produce a coherent and integrated set of findings from where the points and conclusions of this work are derived.

\section{Real del Sol: the Habitat of the Seventh Generation (G7 Habitat)}

At the beginning of 2005 started the construction of a housing development guided by a concept called "Habitat of Seventh Generation" o G7 Habitat. The developers, designers and architects from Real Paraíso Residencial and Conectha, an ISP provider, defined G7 Habitat as a household concept that emerges from sixth previous generations experienced by the domestic household. With the G7 Habitat concept, the designers aimed at the Information and Communications Technologies (ICTs) playing not just a strategic role, but one where they are intrinsically linked and embedded to the basic idea of what a household is. Figure 1 shows a picture of a house in Real del Sol. 


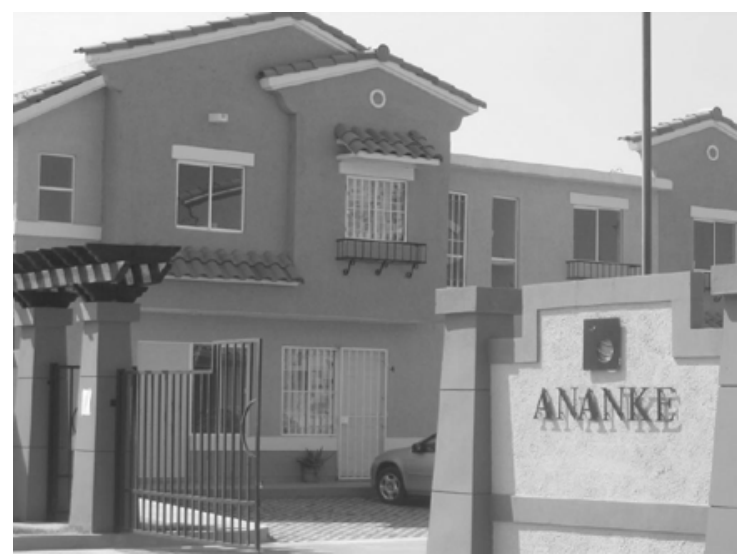

Figure 1. A typical house in Real del Sol. Privada Ananke.

The concept G7 Habitat includes access to high-speed Internet as part of the basic house infrastructure together with water, electricity and sewage drain. Each unit is connected thorough a wireless network that allows speeds up to $340 \mathrm{Kbps}$. Some of the houses also include a personal computer for free or it is offered by Conectha at preferential prices. Through the computer the neighbors have access to a set of services in the neighborhood intranet designed by Conectha. Figure 2 shows a screen shot of the Intranet. The services of the Intranet include: access to security cameras, community information, e-mail, educational content, on-line ordering of grocery and other products.

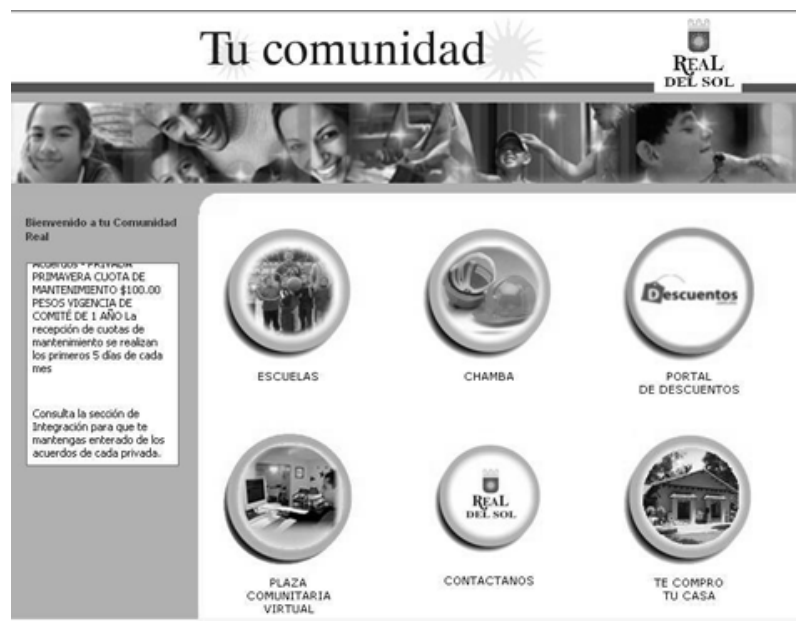

Figure 2. Community Intranet in Real del Sol.

G7 Habitat aims to go beyond providing Internet access to neighbors and provides services that are shaped to the community. For instance, access to the 
security cameras is only allowed to neighbors and just to those cameras of their privadas and common areas. Similarly, the online shopping service links neighbors to small local businesses from Tecamac and Ojo de Agua communities. The Intranet also includes a section where neighbors can get discount coupons from local businesses. Interestingly, the way that online shopping is operating respond to the actual needs of the community. As opposed to other scenarios with transactions are done with credit or debit cards, the transactions in Tecamac are in cash. People order their products online and then the shop delivers the goods by bike or motorbike and charges the costumer in cash at their door.

G7 Habitat was conceived as a concept that encourages community integration. The development counts with two small parks, basketball courts, a primary school, a kindergarten, and other communal areas. To facilitate organization, the development is organized in privadas, groups of ten or twenty houses that are separated of the rest with gates. People in the privadas share some green areas and services (trash bins sections).

\section{Implementing the idea of Habitat Computing: Results and Findings}

In this section we present some of the results emerging from the analysis of data. We analyze the materialization of the idea of Habitat computing through the concept G7 habitat as implemented and proposed by Real Paraiso Residencial. The results are organized in three main areas: (1) the role of Habitat computing as a point of entry when buying a property, (2) the role of Habitat computing to settle in, (3) the role of Habitat computing to support neighborhood coexistence.

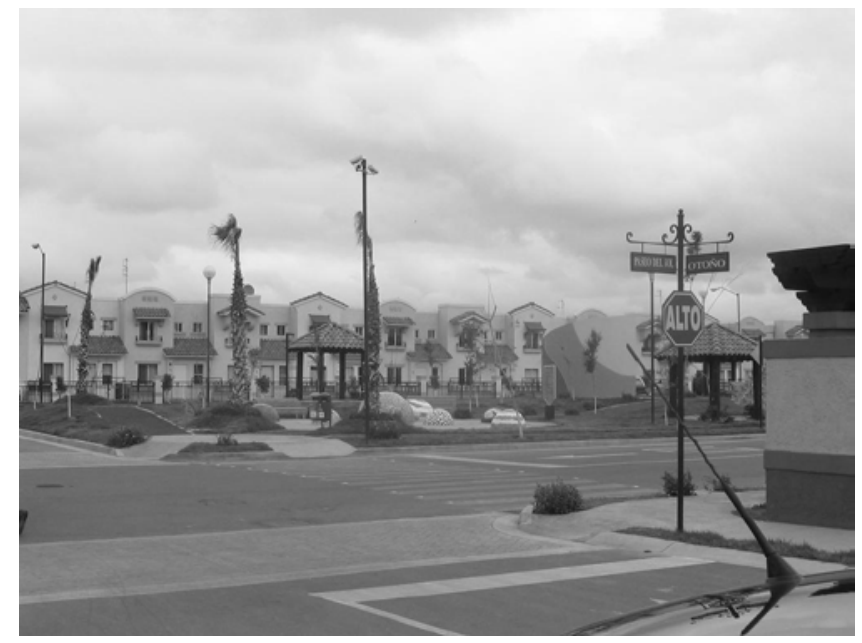

Figure 3. One of the common areas at Real del Sol. 


\subsection{Finding about Real del Sol and deciding about buying a property}

From the beginning of our field work at Tecamac, it was possible to notice how potential buyers of houses in Real del Sol were attracted to visit the demo houses by an extensive advertising campaign which clearly served to portrait the properties as going beyond the typical house of social interest. Phrases such "G7 Habitat", "Concepto G7" or "Tu casa conectada al mundo"" were placed on advertising together with images of Californian style houses linked to images of computer and internet-related symbols. Because this emphasis was present throughout the sale and post-sale process, it was not a surprise that people interviewed were well aware of the concepts and used them as part of their vocabulary to talk about their properties. Perhaps more important is the fact that those concepts were instrumental for neighbors setting their expectations about their property and the life in general at Real del Sol.

As indicated by our interviewees, the concept G7 Habitat certainly served as a marketing tool to attract visitors to the demo houses, but we also noticed that the concept was interpreted in a different way once the decision to make a purchase had to be made. At that stage, the G7 concept seemed to be linked to architectural design, style of the property, rather than to images of a technology-enabled home. We asked the informants to identify the three most persuading reasons to buy a property at Real del Sol. Figure 5 shows a consolidated of mentions of the three reasons to buy. As it can be seen, the most two important aspects were the peace of mind and the G7 habitat concept, followed by the cost of the dwelling.

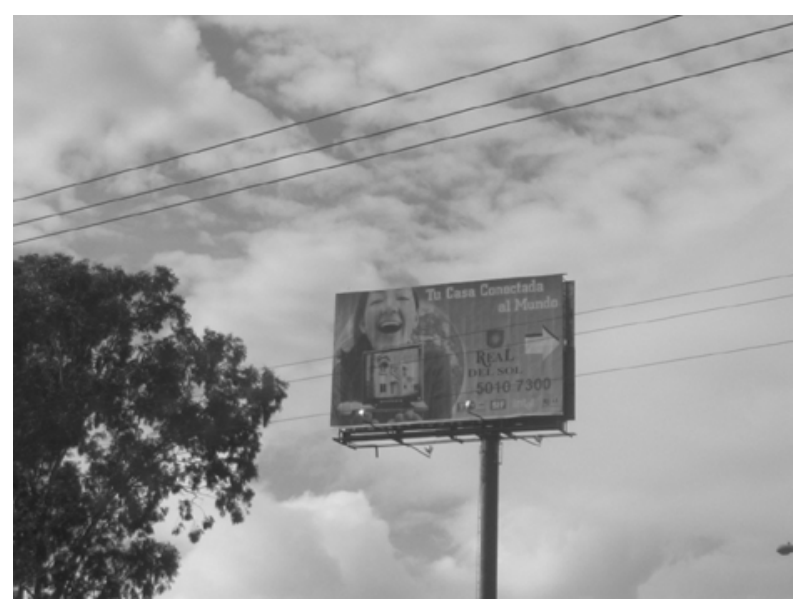

Figure 4. A spectacular with advertising for Real del Sol with the phrase "Tu Casa Conectada al Mundo"

Peace of mind basically refers to the quietness and perceived safety resulting from the zone where Real del Sol is located. Many interviewees commented that the

\footnotetext{
${ }^{2}$ Your home connected to the world
} 
zone is a not so populated area, thus it has lower pollution levels, less traffic, etc. Some of them, contrasting the zone with their old neighborhoods in Mexico City, defining connections between low populated areas and safer contexts, "... the zone is not very populated and consequently not very affected by gangs". Furthermore, informants made clear that in order to assess the level of a security of a property, what counts is not just the household itself, but the area where it is located, as the following informant commented with regard to living in Mexico City "the apartment where I lived was very safe, I mean, the building, but the zone was definitely awful, horrible place, one of the most dangerous areas in the city." To what extent zone takes precedence over individual household characteristics with regards evaluating safety it is not completely clear, but our understanding is that most of our informants considered the area of Tecamac as being safer that Mexico City and this was their starting criteria to evaluate the property.

With similar relevance, when taking a decision in regards of acquiring a property at Real del Sol, was the fact that informants perceived that they were buying a house within distinctive characteristics. Many of them mentioned that they bought "el concepto que me ofrecieron" (the offered concept). However, we found that the actual meaning of the G7 Habitat concept moved from the integrated vision of seven basic services to a more practical meaning. When we asked informants about what they meant by the G7 concept, they often refer and limit their descriptions to aesthetic values. For instance, some of them mentioned that they found the houses very attractive when comparing them to other nearby complexes or properties available through credit programs (e.g., Infonavit): "I actually liked the... the kind of façade... I liked... the finishes... [You see,] I studied Architecture so I was more or less watching [for those aspects]..." commented one of the informants.

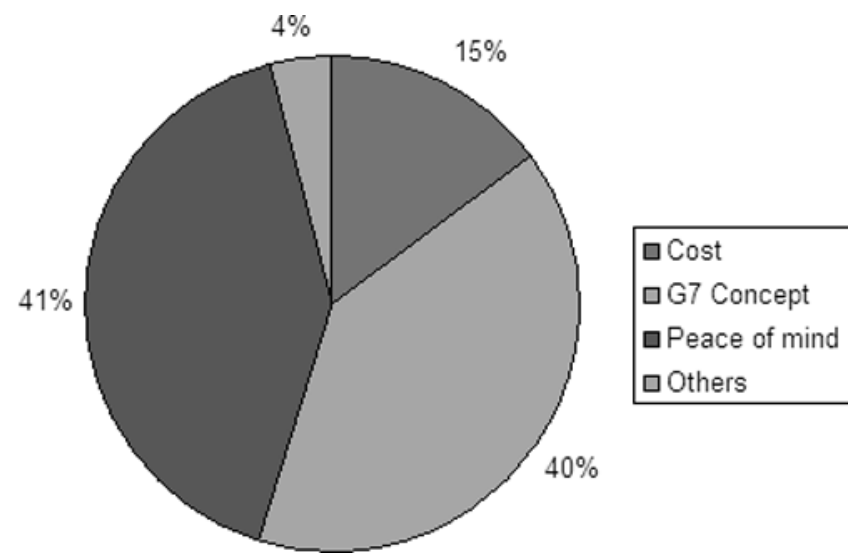

Figure 5. Pie chart with the main reasons to move in

Finally, but less relevant, cost was indicated as a factor influencing the purchase of the property. Neighbors reported that they obtained better value for their money and more pleasant households. One informant, a young housewife, commented "the facades are really nice and the houses are not really expensive..." Similarly, other 
informant pointed out "after I visited some other complexes in the area and even in the DF, I decided that this one was the best deal as offered so many benefits such as construction, finishes and ways of access..." The Californian style of the properties and the individual touch of each one were aspects that were often emphasized by our informants.

The fact that cost was not mentioned as being as relevant as peace of mind or aesthetic design, can be explained by understanding how the properties were purchased. According to data provided by Real Paraiso Residencial, all the informants bought their properties using either government-sponsored or commercial credit schemes. Many of them knew that because they were planning to get a mortgage to pay for the household anyway and because there were many housing complexes offering properties within similar range of price, they had to focus not just on price but other factors.

Considering the great effort to promote the idea of a tech-enabled home connected to the world, we found very relevant that this meaning of the G7 concept was not mentioned as a relevant factor on persuading people to buy the property. Our conclusion is that despite the fact that having a computer and temporal free internet access was attractive for potential buyers, the benefits were not clear at the beginning. Many neighbors were not able to perceive how the vision of "your house connected to the world" would mean for them in practice. Their expectations were based on what they knew about computers and what they were able to do before moving to Real del Sol. Many families already had a computer before coming to Real del Sol and many accessed the Internet regularly. Among the 27 families interviewed, 25 of them owned a computer before moving in. They foresaw that the benefit was that they would be able to access the Internet for free, at least during some period, but they didn't mention other major benefits.

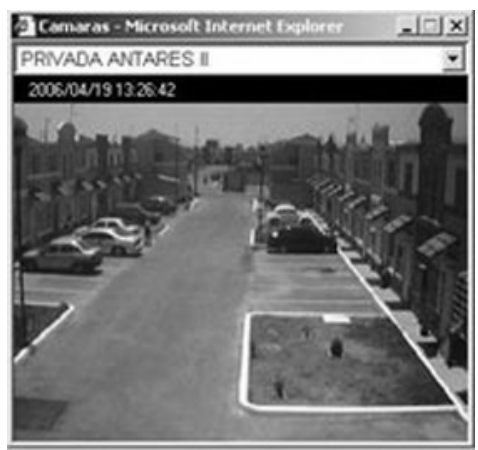

Figure 6. An image from one of the cameras connected to the Internet

We noticed that one of the benefits derived from the technological infrastructure was the possibility for residents to watch their properties while away and mainly before moving in. Because many of the future residents were provided with access to surveillance video cameras, which they could be accessed from any computer connected to Internet, they were enabled to follow up the erection of the house as the 
construction moved on. Some of them, after moving in, were using the cameras not only to keep an eye on their home but also for showing their homes off to their relatives and friends. This benefit indicated that for some neighbors at the early stages after the purchase, the catchy phrase was not "Tu casa conectada al Mundo", but "Tu casa a la vista del Mundo".

\subsection{The experience of moving in}

One of the main challenges when moving to a new residential zone is the fact that the area is very unfamiliar and quotidian activities such as shopping or getting services can turn to be cumbersome. Usually people try to identify shops and services before moving in, but that process can be time-consuming and neighbors end up with just a limited picture of the kind of shops or services in the area. It is generally throughout a process of trial and error that eventually people are able to reestablish their trusted sources. Many of the informants prioritized this identification of services and, particularly for families and for obvious reasons, schools were one of the main things to secure before moving in. However, other services such as auto repair shops, general doctors, and dentist were also mentioned. Going down in terms of priorities, people mentioned services such as electricians, plumbers, carpenters, or gardeners.

Our analysis indicates that by far one of the most successful services provided by the G7 Habitat concept was the online commercial link. Through the commercial link informants reported to have access to a local pharmacy, butchery and a small convenience store. According to people interviewed, this service was particularly relevant and useful during the initial stage when families were settling in. When asked about the usage of the commercial link, informants mentioned that they only used the service when they just moved in and mainly because they did not know what other alternatives were around and did not have time to look for them.

Once neighbors established, people were encouraged to start using the online services provided by Conectha to shop at local stores, but it seems indeed that the usage declined and in most cases simply vanished. When many of the informants who bought at least once using the service were asked about whether they would continue using the service or not, they were not even aware if it was still working. For instance, as part of the conversation about the use of Conectha's services, this is what one neighbor remarked "...and basically, I don't do this every day, but once in a while, for example [what I do is] shopping some meat ...but [now] I don't know what happened... it is temporally... I don't know, maybe the service was too expensive,... paying to be in the web site, right now it says is temporally out of service..." Furthermore, when we asked them if they would continue using the service (assuming it was working), many of them expressed that they preferred to see the groceries they shop and many times they just find the whole experience of going out and shopping more enjoyable.

\footnotetext{
${ }^{3}$ Your house to be seen by the world.
} 


\subsection{Getting to know neighbors and community organizations}

As part of the post-sale service including in the G7 Habitat concept, Real Paraiso Residencial organized and led an initial meeting where neighbors met each other and participated in group exercises aimed to break the ice and incentive social integration. Such meetings were organized once a number of neighbors moved to each privada. The perception of the meetings organized by Real Paraiso was, in general, very positive among the people interviewed. Most of the informants agreed that this was a good way to bring out all the problems, concerns and disquiets. From those meetings people were able to define an organizational structure naming a committee with president, treasurer and secretary, as well as operation rules with regards the monthly maintenance fees and operative schemes.

We found that the fact that post-sale people from Real Paraiso Residencial organized the initial meetings caused the neighbors to develop some sense of dependence on them. For neighbors, it was clear that their organization and operation of their privada committee was independent from the post-sale team. However, at the same time, they expressed that sometimes there were some issues, formerly managed by Real Paraiso Residencial, that they wouldn't have the capacity (or authority) to deal with. Thus, they expressed that the future of the community meetings was uncertain as they feared a dramatic decrease on attendees and even disorganization. A couple commented "...my husband and me were talking about that, I asked him if Real del Sol was always going to be there, if there was always going to be a post-sale department and if they will be always taking care of us or what?" This uncertainty resulted from the lack of information with regards the duration of the post-sale cycle and the level of involvement of Real Paraiso Residencial in the life of the community. Neighbors just speculated about for how long the post-sale service would stay and how the whole community could be governed afterwards.

The main concern from neighbors was about the preservation of the G7 Habitat concept. Again, here the concept was meant to be the architectonic and style characteristics of the household. Informants were worried about the aspect of the complex once Real del Sol leaves and whether or not they would be able to maintain the regulations with regards facades, styles, etc. One of the interviewees commented: "What are we going to do when Real del sol is not there? Who's going to decide what is allowed and what is not?".

Our findings indicate people had crossed feelings with regard to the idea of living in a privada. For many informants the idea of living in a privada resulted attractive initially, but then it turned out to be disruptive in practice. People knew they were moving to a privada-style setting where many of the facilities would be shared (e.g., trash bins areas, gardens). However, the perception of residents is that they were not aware that the privada style of life would require them not just to share some facilities, but to interact with others to achieve collective goals (e.g., paint the common areas). This caused some discomfort among those not used to establish cooperative relationship with neighbors or those stating that their neighbors were not as friendly as they expected.

Other issue concerning the communication and coexistence among neighbors is the fact that many people do not feel engaged at all in a community in terms of their 
responsibilities to achieve a general well being. For instance, we were informed that many people were not so willing to pay the monthly maintenance fees. This caused annoyance for those paying regularly and raised initial signs of conflict among neighbors. Similarly, no all residents were happy with the idea of maintaining the design guidelines for their properties which would preserve their market price. For instance, one of our interviewees expressed some discomfort as he wanted their front door to be different since he had bought already some supplies for a house: "...when I came here, the model houses had these doors, the finishes... and I asked May I change our door? And they said No, because everything has to be in harnony, everything has to be respected... They even told me that I could change the front door as long as I changed its color to white". The interviewee did not see the point of conforming to the rest even that he knew that in the long term the houses could be depreciated as a result of it.

Other incidents reflected the natural challenges of living together such as noisy neighbors or lack of respect for other properties. For instance other interviewee commented that his neighbor was washing her car and all the water went straight to his yard causing a flood. Definitely, these situations cause some distress in the community, but are part of what one can expect from people living together.

On the positive side, we noticed that even at the early stage many informants were concerned about community problems identified as likely community integrators to procure the well-being of all people. These concerns were identified as critical problems by many of the informants. Among them, two have major relevance: the water supply problem and the cow stable located next to Real del Sol.

The stable, as remarked by our informants, is not a minor issue and indeed has already upset some of them. Actually, a woman commented "... We never were told about the stable, perhaps people already told you about, didn't they? ... Yes, it's then... disgusting because there are a lot of flies... and the smell. The smell at the beginning was like... I had headaches, and I didn't know about that! And then I said... 'I was supposed to be running away from pollution' and I came here and it's a stable! The stable is what is dislike more... and the smell is really strong down here, and that actually is a disadvantage and that was precisely what I was telling them the thing is that you gave us a stable as a gift without asking for it and you didn't even tell us, that's the problem!'” Actually people were really concerned about health-related issues because of the flies, mosquitoes and dung.

In regards to the water supply problem, a neighbor was concerned about the fact the well was going to be managed by the municipal government and commented "How can I be sure that the water is going to be enough for us once the government takes the control of the well? What if the adjacent complexes need water?" Such problems and others of that magnitude could be a trigger to make this community a very cohesive and organized group and start working together for the wellbeing of the community. 


\section{Discussion of challenges and revealed opportunities}

Of major importance is the connection between Conectha's Intranet as a point of access and the potential that neighbors would be likely to receive information from this channel. Although many of them had email accounts provided by Conectha's none of the informants (except one) used them as their main account. That was clear when we talked about the services and when we asked them for their email addresses. The fact that they did not use their account is an indication that they are less likely to visit the Intranet and therefore defeats the purpose of posting relevant information there as neighbors would not read it. It is likely that an scheme that either, presents the Intranet as a gateway to access the Internet when using Conectha's network or promotes the use of Conectha's email addresses by providing larger inbox spaces and better functionality would make more effective the communication through this mean.

As part of the technologically-enabled offer of the G7 Habitat concept is the safety of the complex as well as the wellbeing of their inhabitants. This was a palpable challenge faced by the informants, perhaps the most important. Peace of mind, as remarked by our informants, is a priority, and that was one of the main reasons of why they moved to Real del Sol. Thus, adequate, sophisticated equipment should be then provided to security services in order to accomplish their work appropriately since one of the main worries of the neighbors has to do indeed with safety and security. The G7 Habitat concept aimed to address this issue by providing security video cameras in the privadas and in some public areas of the complex. However, neighbors soon became aware of some issues regarding the video cameras. Firstly, the security staff did not monitor the security cameras. Secondly, even if they decided to monitor them by themselves, the level of detail and quality of the image was not optimal, and finally, perhaps the most important, no video-recording was done, thus eliminating the possibility of analysis in case of robberies.

Finally, another challenge we found for the fully implementation of the G7 concept is that many neighbors feel that the absence of Real Paraiso Residencial, as mentioned before, will dishearten others and they were very concerned about this as they have already faced confrontations and disagreements among them because of the regulations and the lack of an entity as a moderator.

As the study moved on, some insights emerged as opportunities to improve current and future developments. The information gained from the interviews with regards to the services offered to neighbors should be classified in 1) moving-in services and 2) daily-living services. The former refers to the services offered when the residents are moving in such as a set of basic domestic products. On the other hand, the latter refers to the services needed when the residents are already settled in, such as medical services, stationery stores and an eBay-like Web site to enable neighbors to sale used items among them. 

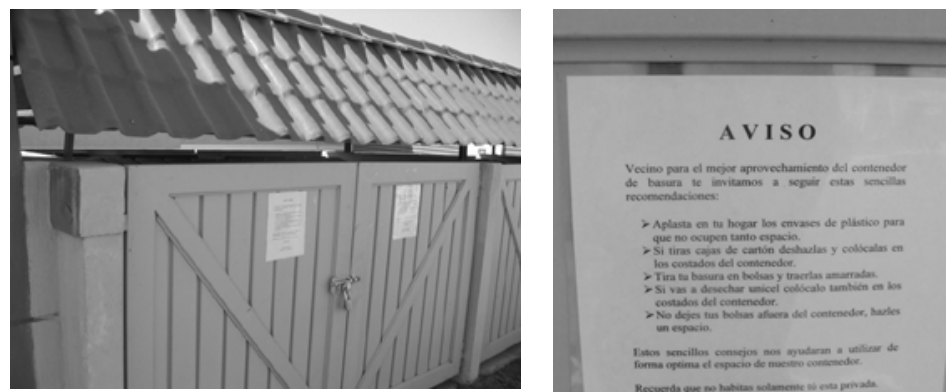

Figure 7. A public notice on one of the privada's entrances giving instructions about the use of trash bins

Finally, we found that the needs of communication among neighbors could be fulfilled in a better way. We found that Conectha e-mail account is not very popular among the residents. Moreover, not everybody even owns a computer. The residents have fulfilled this need of communication with pieces of paper posted on the houses' front doors and public places such as the school. Regarding this, one resident commented "... we use little pieces of paper glued on the walls, this because I know that not all the $100 \%$ of the inhabitants either has a computer or visits the Conectha website". One solution that might encourage the use of the Web site is an electronic posting service together with a public display such as the ones used in most banks (e.g., led-based displays).

\section{Conclusions}

This paper presented the results of an initial analysis of data gathered through a set of interviews conducted with families from a suburban area of Mexico City by the end of February, 2006, where neighbors were provided with computers and internet as part of the facilities.

From a technological standpoint, our results indicated that the implementation of ICTs to support daily life in residential communities experienced radical and unpredictable adaptations. Our findings confirm that the full adoption of any technology should be in terms of the relative usefulness perceived by users, but this perception of usefulness can change with time or just be supported by undiscovered needs which become evident once people interact with the technology. The case of the online commercial link illustrate the former point and the security cameras the latter point. Moreover, even when the technological scenario presented in this paper can be somewhat simplistic, our findings revealed that a lot of social issues might arise thus hampering the proper adoption and use of the services provided. This experience suggest that the implementation of fully tech-enabled houses such as efforts made by MIT [10] and Georgia Tech [11] may be still far away from now thus leaving them somewhat futuristic. Although these latter projects are aimed at other purposes rather than facilitating the interactions and coexistence between neighbors, results from our study suggest that social implications are often left aside 
when designing, developing and implementing technology that is intended to alter the 'natural' manner people carry out quotidian things.

On the other hand, the experience itself at Tecamac indicate that the proposal of the G7 Habitat concept as a technology-enabled household served well as a marketing tool and promoted the first contact with the housing development. However, as people moved to the step of taking a decision with regards of buying the property, the most important criteria is to have peace of mind by living in a safe, secure environment. As we continue our study, collection and analysis of our data, we expect to consolidate a solid understanding of some of the issues expressed here and the way people at Real del Sol are experiencing a home connected to the world. Finally, we believe that studies such us this one are of paramount importance as they provide valuable insights and implications for the design and deployment of technology in real communities on a large scale.

\section{References}

[1] AMIPCI, "Hábitos de los Usuarios de Internet en México 2005." Oct, 2005.

[2] INEGI, "Encuesta Nacional sobre Disponibilidad y Uso de Tecnologías de la Información en los Hogares.," 2005.

[3] M. Foth and M.Brereton, "Enabling local interaction and personalized networking in residential communities through action research and participatory design," in OZCHI 2004: Supporting community interaction, P. Hyland and L. Vrazilic, Eds. Wollongong, NSW: University of Wollongong, 2004, pp. 20-24.

[4] MexicoUnido.org, "Mexico Unido por la Democracia," in http://www.mexicounido.org/, 2006.

[5] S. Low, "Behind the Gates," New York and London: Routledge, 2003.

[6] M. Foth, "Analyzing the Factors Influencing the Successful Design and Uptake of Interactive Systems to Support Social Networks in Urban Neighborhoods," International Journal of Technology and Human Interaction, vol. 2, pp. 65-82, 2006.

[7] J. M. Carroll and M. B. Rosson, "A Trajectory for Community Networks," The Information Society, vol. 19, pp. 381-393, 2003.

[8] M. Gurstein, "Community informatics, community networks and strategies for flexible networking," Commumity informatics: Shaping computermediated social relations, pp. 263-283, 2001.

[9] J. Corbin and A. Strauss, "Basics of Qualitative Research," Thousand Oaks (CA): Sage Publications, 1998.

[10] S. Intille, K. Larson, and C. Kukla, "House_n: The MIT Home of the Future Project," MIT Dept. of Architecture. http://architecture.mit.edu/house_n, 2000.

[11] X. Bian, G. D. Abowd, and J. M. Rehg, "Using Sound Source Localization to Monitor and Infer Activities in the Home," Georgia Institute of Technology Report Number: GIT-GVU-04-20, 2004. 